\title{
Monocyte expressed macromolecular C1 and C1q receptors as molecular sensors of danger: implications in
} SLE

\author{
Berhane Ghebrehiwet ${ }^{1}{ }^{*}$, Kinga K. Hosszu ${ }^{1}$, Alisa Valentino ${ }^{1}$, Yan $\mathrm{Ji}^{1}$ and Ellinor I. B. Peerschke ${ }^{2}$ \\ ${ }^{1}$ Departments of Medicine and Pathology, Stony Brook University, Stony Brook, NY, USA \\ 2 Departments of Laboratory Medicine, Memorial Sloan-Kettering Cancer Center, and Laboratory Medicine and Pathology, Weill-Cornell Medical College, New York, \\ NY, USA
}

\section{Edited by:}

Nicole Thielens, Université Joseph

Fourier, France

Reviewed by:

Francesco Tedesco, University of Trieste, Italy

Anna Erdei, Eötvös Loránd University, Hungary

\section{*Correspondence:}

Berhane Ghebrehiwet, Health

Sciences Center, Stony Brook

University School of Medicine, T-16,

Room 040, Stony Brook, NY

11794-8161, USA

e-mail:berhane.ghebrehiwet@

stonybrook.edu
The ability of circulating blood monocytes to express $\mathrm{C} 1 \mathrm{q}$ receptors (cC1qR and $\mathrm{gC} 1 \mathrm{qR}$ ) as well as to synthesize and secrete the classical pathway proteins $\mathrm{C} 1 \mathrm{q}, \mathrm{C} 1 \mathrm{r}$, and $\mathrm{C} 1 \mathrm{~s}$ and their regulator, $\mathrm{C} 1-\mathrm{INH}$ is very well established. What is intriguing, however, is that, in addition to secretion of the individual $\mathrm{C} 1$ proteins monocytes are also able to display macromolecular $\mathrm{C} 1$ on their surface in a manner that is stable and functional. The cell surface $\mathrm{C} 1$ complex is presumably formed by a $\mathrm{Ca}^{2+}$-dependent association of the $\mathrm{C}_{1} \mathrm{r}_{2} \cdot \mathrm{C} 1 \mathrm{~s}_{2}$ tetramer to $\mathrm{C} 1 \mathrm{q}$, which in turn is anchored via a membrane-binding domain located in the $\mathrm{N}$-terminus of its A-chain as shown previously. Monocytes, which circulate in the blood for 1-3 days before they move into tissues throughout the body, not only serve as precursors of macrophages and dendritic cells (DCs), but also fulfill three main functions in the immune system: phagocytosis, antigen presentation, and cytokine production. Since the globular heads of $\mathrm{C} 1 \mathrm{q}$ within the membrane associated $\mathrm{C} 1$ are displayed outwardly, we hypothesize that their main function - especially in circulating monocytes - is to recognize and capture circulating immune complexes or pathogen-associated molecular patterns in the blood. This in turn may give crucial signal, which drives the monocytes to migrate into tissues, differentiate into macrophages or DCs, and initiate the process of antigen elimination. Unoccupied $\mathrm{C} 1 \mathrm{q}$ on the other hand may serve to keep monocytes in a pre-dendritic phenotype by silencing key molecular players thus ensuring that unwarranted DC-driven immune response does not occur. In this paper, we will discuss the role of monocyte/DCassociated $\mathrm{C} 1 \mathrm{q}$ receptors, macromolecular $\mathrm{C} 1$ as well as secreted $\mathrm{C} 1 \mathrm{q}$ in both innate and acquired immune responses.

\section{Keywords: c1q, DC and C1, monocyte C1, C1q in SLE, C1q in autoimmunity, C1q and C1q receptors}

\section{INTRODUCTION}

Monocytes serve a critical role in adaptive and innate immunity not only by serving as precursors of macrophages and myeloid dendritic cells (DCs), but also by their function in phagocytosis, antigen processing, and presentation, as well as secretion of pro- and anti-inflammatory cytokines. Monocytes are produced by the bone marrow from hematopoietic stem cell precursors called monoblasts, and circulate in the bloodstream for about 3 days before they migrate into tissues throughout the body where they develop into different types of macrophages and DCs (1, 2). Although their inherent plasticity allows them to develop into various types and subtypes, three major types of blood monocyte subpopulations are recognized: the classical monocyte or CD14++ CD16-, which expresses high level of the LPS receptor (CD14) but no expression of $\mathrm{Fc}$ receptor (CD16), and the

Abbreviations: $\mathrm{cClqR}$, receptor for the collagen-like region of C1q; DC, dendritic cell; $\mathrm{gClqR}$, receptor for the globular heads of C1q; iDC, immature DC; $\mathrm{mDC}$, mature DC. non-classical monocyte or CD14+CD16++ characterized by low level expression of CD14 but higher level of CD16 expression. The third is an intermediate between the two, which expresses high level CD14 but low level CD16 (CD14++ CD16+) and is postulated to serve as a transitory link in the maturation process of the classical monocyte into the activated, non-classical monocyte $(1,2)$. The various monocyte types have been shown to exhibit distinct phenotype and function. Upon activation with microbial antigens, the non-classical monocytes are activated to produce high amounts of pro-inflammatory cytokines including tumor necrosis factor and IL-12 and exhibit higher potency in antigen presentation.

One of the major functions of blood monocytes is to eliminate antibody- or complement-opsonized microbes through either phagocytosis or by binding directly to the pathogen via patternrecognition receptors (PRRs) that recognize pathogen-associated molecular ligands (3). Emerging among these PRRs are $\mathrm{cClqR}^{2}$ and $\mathrm{gClqR}$, which in addition to their primary ligand, $\mathrm{Clq}$, can also independently recognize a vast array of plasma proteins as well as pathogen-associated molecular ligands $(4,5)$. Moreover, 
monocytes express on their surface an intact macromolecular C1 as well as C1-INH $(6,7)$ with the globular heads free to recognize antigens. However, despite the available body of evidence showing the presence of macromolecular $\mathrm{C} 1$ on the surface of circulating blood monocytes (7), not much is known about its physiologic function. Based on the available data, we postulate that $\mathrm{Clq}-$ within the $\mathrm{C} 1$ complex expressed on circulating monocytes - may serve not only as a molecular sensor of danger but also as a molecular guarantor of steady state. Thus, while in the steady state, $\mathrm{C} 1 \mathrm{q}$ within the $\mathrm{C} 1$ complex would regulate early processes that maintain cells in the monocyte or monocyte-like lineage, (innate immunity); recognition of "danger" would impart a license that drives monocytes toward the DC lineage (adaptive immunity). Deficiency in $\mathrm{Clq}$ therefore would disrupt this equilibrium.

\section{DENDRITIC CELLS AND AUTOIMMUNE DISEASES}

Dendritic cells are a complex lineage of antigen presenting cells (APCs) that orchestrate a variety of immune responses $(3,8-$ 14). Although B and T cells are known to be the mediators of acquired immunity, their function is under the control of DCs. DCs in various stages of maturity capture, process and present antigens, express lymphocyte co-stimulatory molecules when activated, migrate to lymphoid organs, and secrete cytokines to initiate immune response (9). While B cells, the precursors of antibodysecreting cells, can directly recognize native antigen through their $\mathrm{B}$-cell receptors, $\mathrm{T}$ lymphocytes need the antigen to be processed and presented to them by APCs such as DCs. The T cell antigenreceptors (TCRs) recognize fragments of the processed antigens bound to MHC molecules on the surface of DCs (9). The peptidebinding molecules on the APC are of two types: MHC class I (MHC I), which stimulates cytotoxic CD8+ T cells, and MHC class II (MHC II), which stimulates helper CD4+ T cells (8). A second co-stimulatory signal that is critical for $\mathrm{T}$ cell activation is the interaction of CD28 on the T cell and CD80/CD86 on the APC such as DC. In addition to their ability to activate lymphocytes, DCs can also tolerize T cells to self-antigens by a variety of mechanisms including the production of regulatory cytokines such as IL-10 and the induction of regulatory T cells $(11,14)$.

Dendritic cell precursors circulate in the bloodstream as monocytes, which are continuously generated from bone marrow progenitors. Migration into non-lymphoid organs induces differentiation of DC precursors into DCs that become resident tissue cells of the interstitium of peripheral organs or skin (9). These tissueresident DCs are thought to be in an immature state [immature DCs (iDCs)] and are specifically characterized by high phagocytic activity and the ability to capture self and foreign antigens. The presence of specific lectins, such as DC-SIGN, Langerin, and mannose receptors on their surface allows iDCs to recognize invading bacteria or viruses $(10,13)$. Moreover, the expression of molecules such as $\alpha_{\mathrm{V}} \beta_{5}$ integrin and CD91 enables them to recognize and engulf self-antigens including those associated with apoptotic cells (10). Therefore, imDCs can interact with self-components, and virtually every antigen present in the periphery can be processed after engulfment and presented as peptide-MHC complexes on the DC surface $(8,11)$. Fortunately, tolerogenic mechanisms exist to prevent inappropriate autoimmune responses. Presumably, under steady state conditions DCs remain immature and start migrating towards lymph nodes upon partial activation signaling. Once they have reached the $\mathrm{T}$ cell area, these semi-mature DCs may induce tolerance by numerous mechanisms $(3,11,14)$. In contrast, when DCs encounter a peripheral microenvironment characterized by pro-inflammatory factors and antigenic material, massive migration and maturation is triggered by molecules such as LPS, bacterial DNA, and double stranded RNA, which are recognized by specific Toll-like receptors $(3,12)$. Cytokines such as TNF- $\alpha$ and IL-1 $\beta$ found in the inflammatory compartment are also important participants in the DC maturation/activation process (9). The maturation of DCs is associated with the up-regulation of co-stimulatory molecules such as CD40, CD80, CD86, and CD58, secretion of cytokines, such as TNF- $\alpha$, IL-6, and IL-12p70, the loss of endocytic phagocytic receptors, high levels of MHC I, II, CD83, and acquisition of high cellular mobility (13). The mature DCs migrate to the $\mathrm{T}$ cell areas of local lymph nodes where they are retained via specific chemokine interactions involving CCR7. Subsequent screening events result in engagement of the appropriately matched T cell-MHCI/MHCII receptors. Priming of naïve CD4+ T cells takes place when DCs engage CD40L. Because of their unique ability to initiate immune responses against invading pathogens as well as against peptides derived from self-proteins, DCs play an important role in the development of autoimmune diseases. However, a variety of mechanisms impact on the immunogenicity of DC in order to prevent autoimmune responses including local factors that facilitate decisions about the nature and subset of T cell response (15-18). The various signals that influence the DC are not yet fully elucidated, but these signals are likely to depend on the type and dose of antigen, the microenvironment of the DC-antigen encounter, the number, subset, and phenotype of the DC involved, the microenvironment of the secondary lymphoid organs where the antigen is presented, and finally the local synthesis of modulatory proteins including complement proteins, such as C1q, and its C1q receptors each of which is capable of recognizing and capturing self or non-self antigens.

\section{EXPRESSION OF C1 AND C1q RECEPTORS ON MONOCYTES AND DENDRITIC CELLS}

The synthesis of the subunits of the $\mathrm{C} 1$ complex (C1q, C1s, C1r), and its regulator $\mathrm{C} 1$ inhibitor $(\mathrm{C} 1-\mathrm{INH})$ by human monocytes has been shown independently by several investigators $(6,19-24)$. However, the expression of the intact macromolecular $\mathrm{C} 1$ on the cell surface of monocytes and DCs has been described only recently (7). The first indication of the existence of a membrane form of C1 was intimated by the finding that monocyte-derived macrophages were able to synthesize and express a membrane anchored form of C1q (25). Furthermore, these original experiments showed that: (i) the surface expressed C1q was tightly and irreversibly anchored into the cell surface membrane with its globular heads displayed outwardly as evidenced by the fact that it was able to bind Fc, polyanions, the lipid A part of LPS, Gram-negative bacteria such as S. minnesota, as well as porins (outer membrane bacterial proteins); (ii) the A-chain of C1q contains amino acid sequences with properties characteristic of an integral type II membrane protein; and (iii) the surface molecule could only be liberated by detergent or repeated freeze-thawing $(26,27)$. However, these observations presumed that macrophages and not their monocyte precursors 


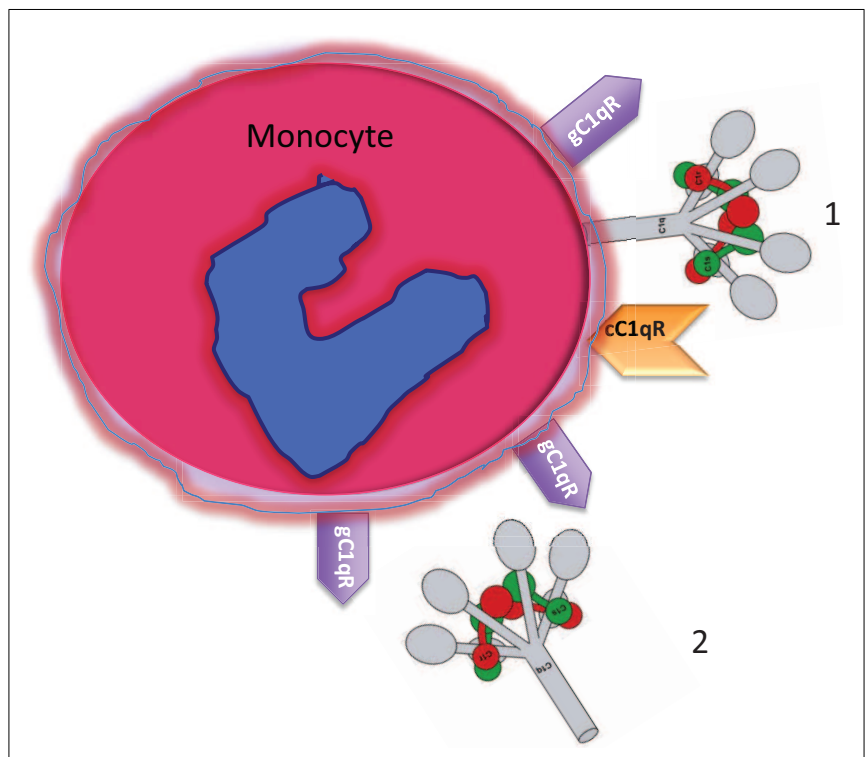

FIGURE 1 | Circulating blood monocytes express C1 and C1qRs. (1) Membrane anchored C1q displays its globular heads free to interact with antigens or immune complexes. (2) Some of the membrane anchored $\mathrm{C} 1 \mathrm{q}$ is cleaved off and secreted into the pericellular milieu and is able to bind to the cell surface via $\mathrm{gC} 1 \mathrm{qR}$. The $\mathrm{C} 1 \mathrm{q}$ figure was obtained from Gérard Arlaud.

were able to express $\mathrm{Clq}$ on their surface. Using more sensitive assays and antibodies, recent experiments from our laboratory have shown that non-stimulated circulating blood monocytes are also able to both synthesize and express all of the components of $\mathrm{C} 1$ (C1q, C1r, C1s) as well as C1-INH (7). The C1 complex is presumably assembled around the $\mathrm{Clq}$ molecule in a manner that is similar to the $\mathrm{C} 1$ complex in plasma, with the $\mathrm{C} 1 \mathrm{q}$ molecule serving as an anchored backbone to which the $\mathrm{C}_{1} \mathrm{r}_{2} \cdot \mathrm{C} 1 \mathrm{~s}_{2}$ tetramer is linked via $\mathrm{Ca}^{2+}$ ions. Such a configuration, which is similar to the natural configuration of plasma C1 (Figure 1) would allow the exposure of the globular heads for immune complex binding or antigen recognition and complement activation. This assumption is also corroborated by the finding that the U937 expressed $\mathrm{C} 1$, is able to activate complement (7), and this activation is closely controlled by C1-INH, present on or near the cell surface (6). Collectively, the data suggest that the surface-associated $\mathrm{C} 1$ complex can initiate complement activation in response to an extracellular Ag and thus may represent the earliest response to either pathogen-associated or modified self-associated danger signals in blood.

The expression of C1q on monocytes is dependent on the maturation stage (Figure 2). While activated monocytes (macrophages) and immature DCs express elevated levels of C1q, this ability is lost when iDCs transition into mature DCs (mDCs) $(28,29)$. Interestingly, this expression profile is also mimicked by both $\mathrm{Clq}$ receptors $(\mathrm{cClqR}$ and $\mathrm{gClqR})$, which in turn are co-localized with $\mathrm{Clq}$ and DC-SIGN on iDCs suggesting that $\mathrm{C} 1 \mathrm{q} / \mathrm{gClqR}$ may regulate DC differentiation and function through the DCSIGN-mediated induction of cell-signaling pathways (30). While inflammatory cytokines and LPS, which induce maturation of DCs, downregulate surface expression of both C1qR molecules, cytokines, and drugs such as IL-10, TNF $\alpha$, or dexamethasone, that keep DCs phenotypically and functionally immature significantly upregulate the expression of both C1qRs (28).

The significance of C1q in the development of autoimmune diseases such as systemic lupus erythematosus (SLE) has been known for many years (31-33), and its potential role in tolerance induction has been proposed $(34,35)$. However, neither the mechanism by which $\mathrm{C} 1 \mathrm{q}$ determines the activation thresholds of $\mathrm{B}$ and $\mathrm{T}$ cells nor how $\mathrm{Clq}$ deficiency causes incomplete maintenance of peripheral tolerance is clearly understood. The fact that $\mathrm{Clq}$ is colocalized with a number of surface molecules such as DC-SIGN, $\mathrm{gClqR}$, and $\mathrm{cClqR}$-implies that these molecules may collaborate in antigen recognition and processing (30).

\section{C1 DEFICIENCY AND SLE}

Systemic lupus erythematosus - a prototype of a systemic autoimmune disease - affects close to three-quarters of a million individuals in the US and a much higher number worldwide with a frequency that varies by race and ethnicity with higher rates reported among Black and Hispanic people (36). Although it is a multifactorial disease, there is an overwhelming clinical evidence showing that homozygous deficiency in any of the classical pathway proteins - C1q, C1r, C1s, C4, and C2 - predisposes an individual to develop SLE and other autoimmune diseases such as rheumatoid arthritis (RA) $(31,33,37)$. Among these proteins, C1q takes a prominent stage in significance as homozygous deficiency or hereditary deficiency due to mutation in the C1q gene is regarded as a strong susceptibility factor for the development of $\operatorname{SLE}(31,33)$. The majority ( $\geq 95 \%)$ of the known individuals with $\mathrm{C} 1 \mathrm{q}$ deficiency are known to have developed clinical syndromes closely related to $\operatorname{SLE}(31,33,38,39)$. Interestingly, the majority of the circulating antibodies in SLE are against "modified self" or intracellular proteins (nuclear or cytoplasmic), suggesting that $\mathrm{C} 1 \mathrm{q}$ may play an important role in the regulation and processing of these antigens.

There has been an exponential increase in recent years exploring the possibility that $\mathrm{Clq}$ is a major link between innate and acquired immunity. Some of these studies have been made possible in part due to the availability of $\mathrm{Clq}^{-1-}$ animal models (40). As an archetypal pattern-recognition molecule with the ability to sense a wide variety of targets, Clq can engage a broad range of ligands ranging from pathogen-associated molecular ligands (non-self) to damage-associated molecular targets (altered self) - including "eat me" signals such as self DNA and phosphatidylserine, which are the first structures exposed at the apoptotic cell surface (41-45). These interactions are able to trigger a multiplicity of immunologic functions, which by and large are beneficial to the host. It is not therefore surprising that deficiency in $\mathrm{Clq}$ leads to various diseases including otitis media, meningitis, pneumonia $(31,34,37)$ as well as autoimmune diseases, such as $\operatorname{SLE}(31,46,47)$. Several reports have shown that C1q can bind via its globular "heads" to the surface of apoptotic cells $(44,47)$; and the common autoantigens targeted in SLE are found in high concentrations on the surface of apoptotic cells $(44,47)$. However, although it is clear that C1q and its receptors play a role in removal of self-waste $(44,47-50)$ the existence of functionally redundant pathways for apoptotic body clearance gives credence to the postulate that autoimmunity arising from diminished $\mathrm{Clq}$ activity could reflect another role of 


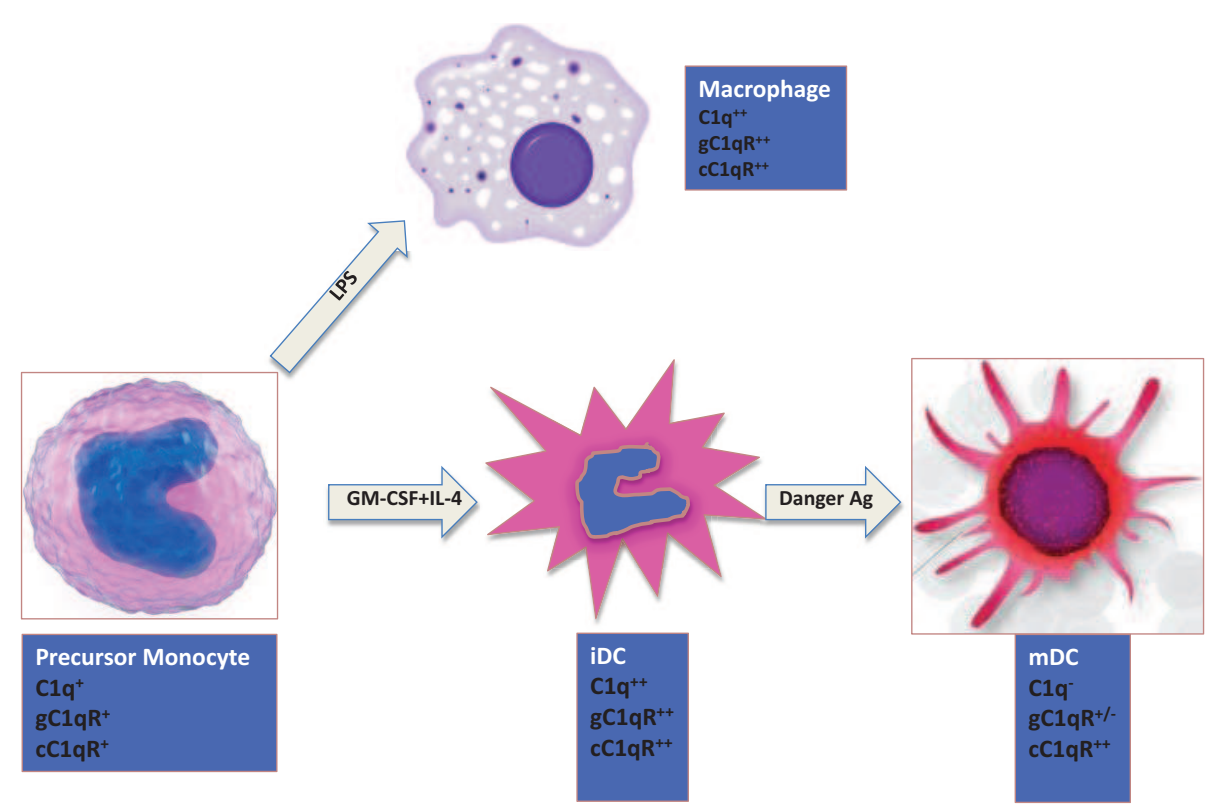

FIGURE 2 | Expression of C1q and C1qRs is maturation dependent. Circulating monocytes express both $\mathrm{C} 1$ and $\mathrm{C} 1 \mathrm{qRs}$, which increase during the monocyte to iDC transition in the presence of self- or foreign-danger signals. Fully mature DCs, however, express little or no $\mathrm{C} 1 \mathrm{q}$, low gC1qR but high cC1qR.

C1q in maintaining tolerance (34). Thus, while C1q could provide active protection from autoimmunity by silencing key molecular markers or regulating autoreactive immune cells, its absence or defective expression could lead to a loss of peripheral tolerance as a cumulative result of impaired apoptotic cell clearance in conjunction with negative signaling. For example, incubation of C1q with $\mathrm{T}$ cells has been shown to inhibit $\mathrm{T}$ cell proliferation presumably by binding to $\mathrm{gCl} \mathrm{qR}$ on the $\mathrm{T}$ cell surface (51) since this activity is mimicked by incubation of cells with mAb 60.11, which recognizes the $\mathrm{C} 1 \mathrm{q}$ binding site on $\mathrm{gC1qR}$. Furthermore, although its role is not precisely known, soluble $\mathrm{gClqR}$ is able to bind CD4 thereby blocking HIV-1 viral entry into T cells (52). More importantly, because of its heterotrimeric nature and oligomeric structure - with two distinct structural and functional domains ( $\mathrm{gClq}$ and $\mathrm{cClq}$ ) - C1q is also able to interact with cell surface receptors via either its $\mathrm{cClq}$ or $\mathrm{gClq}$ domains. Similar to $\mathrm{Clq}$, the $\mathrm{Clq}$ receptors are differentially expressed as monocytes go through the maturation process to become mDCs (35). When monocytes are cultured in the presence or absence of GM-CSF + IL-4, nearly all monocyte-derived DCs expressed $\mathrm{gClqR}$ on day 0 (Figure $3 \mathrm{~B}$ ), while $\mathrm{cClqR}$ was more variable within the population (Figure 3A), despite the consistently elevated expression of its putative surface partner, CD91 (Figure 3C). Even though there was a modest reduction in $\mathrm{gClqR}^{+}$cells by day 4 (Figure 3B), the percent of $\mathrm{cClqR}$ expression increased compared to day 0 (Figure 3A). Furthermore, mean fluorescence index (MFI) analysis revealed that the amount of $\mathrm{cClqR}$ was dramatically amplified after day 2 (Figure 3D), whereas the amount of $\mathrm{gClqR}$ remained at relatively steady levels (Figure $3 \mathrm{E}$ ). Thus, at the precise period ( $\sim$ day 3 ) corresponding to firm commitment to the DC lineage there is an inverse correlation between $\mathrm{gClqR}$ and
$\mathrm{cC} 1 \mathrm{qR}$ expression on the cell surface, which in turn may influence the nature and specificity of the cells' response to C1q. Interestingly, despite the increase in $\mathrm{CC} 1 \mathrm{qR}$ expression, its surface partner, CD91, was gradually reduced during the culture period, indicating that alternate partners for $\mathrm{cClqR}$ are present upon commitment to the DC lineage (Figures 3C,F). Taken together, these data suggest that the regulatory effects of $\mathrm{Clq}$ on DC differentiation and function may depend on specific $\mathrm{C} 1 \mathrm{q} / \mathrm{C} 1 \mathrm{qR}$ interactions; and these interactions may in turn control the transition from the monocyte state (innate immunity) toward the professional APC state (adaptive immunity). The observation that soluble C1q functions as a "molecular switch" during the narrow window - i.e., at the precise period ( day 3 ) corresponding to firm commitment to the DC lineage - of monocyte to DC transition (35) not only explains why $\mathrm{C} 1 \mathrm{q}$ is primarily synthesized, expressed, and secreted by potent APCs, but also why its absence can impair antigen uptake and tolerance.

On the basis of the available data and our own recent findings (35), we speculate that soluble $\mathrm{Clq}$ induces inflammatory responses by binding through its gClq to pathogenassociated molecular patterns (PAMPs) and to modified self antigens (DAMPs), and stimulates phagocytic cells through interactions of its $\mathrm{cClq}$ domain with $\mathrm{cClqR}$. According to this hypothesis, a normal response to "danger" would involve up-regulation of $\mathrm{cClqR}$ on iDC to ensure uptake of noxious agents utilizing the Ag-retrieving functions of C1q $(44,48)$. In the context of inflammatory stimuli, DC maturation would ensue allowing adaptive immune responses against the initiating agent. In contrast, $\mathrm{Clq}$ that is free of antigenic cargo (i.e., in the absence of danger) does not support full commitment to the DC lineage, and instead keeps them in a monocytic phenotype as represented during steady state. 

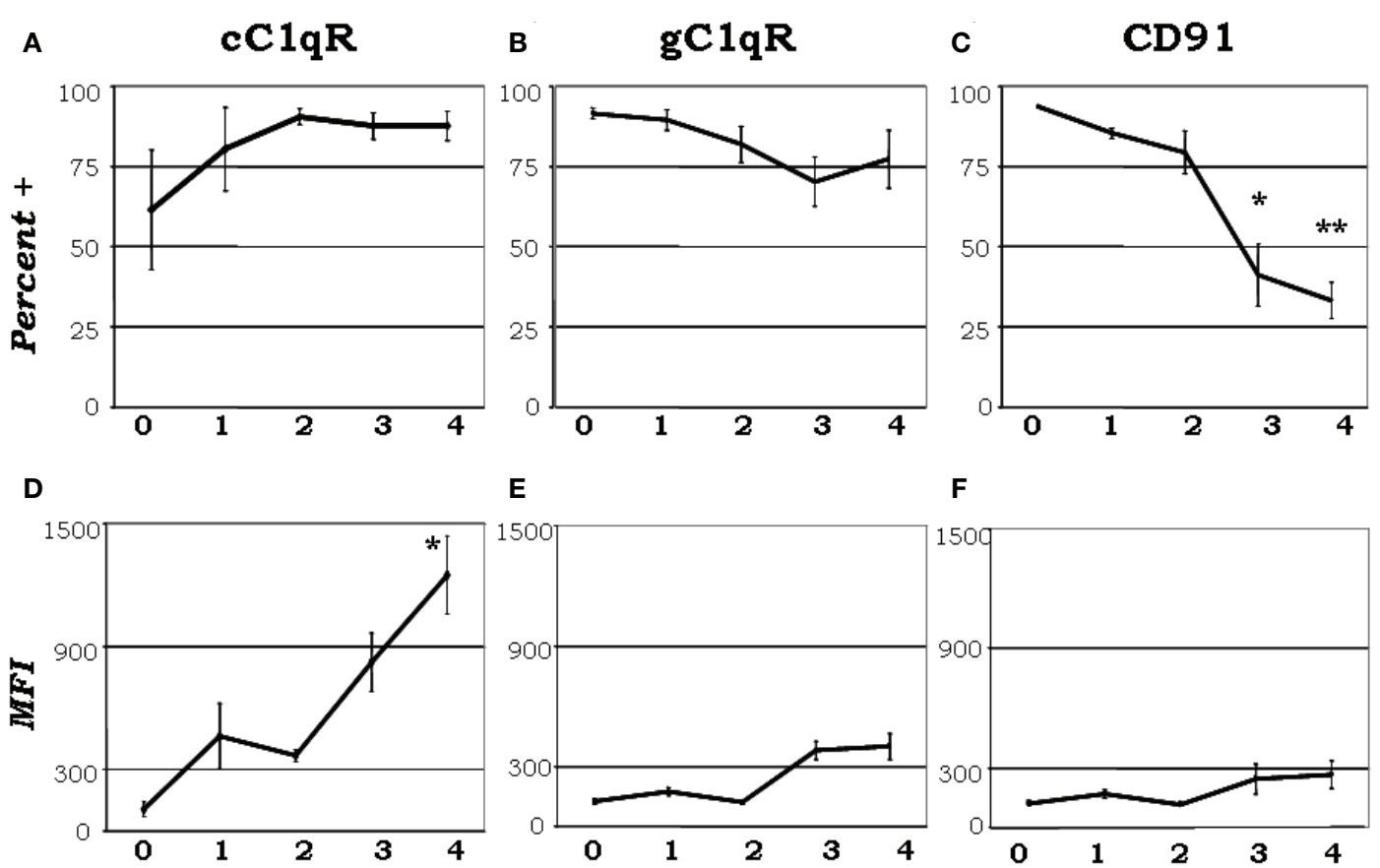

E

F
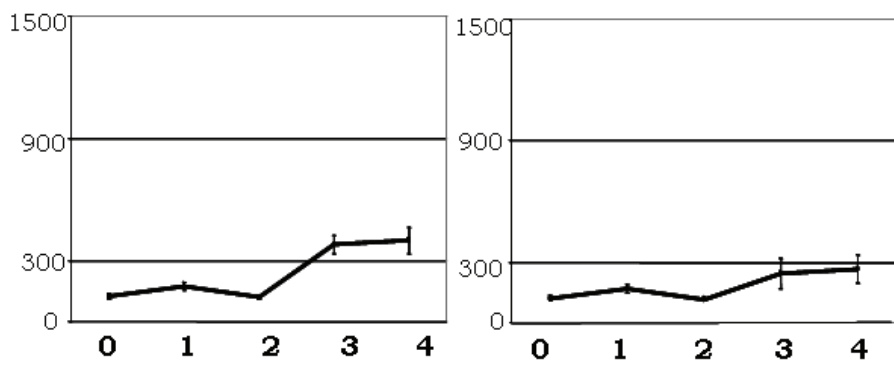

Days in culture

FIGURE 3 | Maturation dependent expression of C1qRs. C1q receptors show varied expression on mono-DC precursors. Mononuclear cells were cultured in the presence of GM-CSF + IL-4, and collected and analyzed on days $0-4$ for the expression of CC1qR (A,D), gC1qR (B,E), and CD91 (C,F) for both percent expression (A-C) and MFI (D-F). (A) The percent of cC1qR expression was variable on monocytes, but by day 2 nearly all monocyte-DCs had the receptor on their surface. (B) On day $0, \mathrm{gC} 1 \mathrm{qR}$ was present on almost all the cells, and its expression was only slightly reduced by day 4 . (C) Monocytes expressed CD91 on their surface, but the percentage of CD91+ cells was significantly reduced by day 3 and 4. (D) Mean fluorescence analysis revealed that $\mathrm{CC} 1 \mathrm{qR}$ expression was dramatically amplified by day 3 and 4. (E,F) gC1qR and CD91 MFIs remained at relatively steady levels throughout the days. Experiments were gated on $\mathrm{DR}+$ cells, ${ }^{*} p<0.05$, ${ }^{* *} p<0.01(n \geq 4)$ [adapted from Ref. (35)].
Therefore, during normal physiology, return to steady state levels of $\mathrm{Clq} / \mathrm{ClqR}$ on monocytes and/or DC precursors would resume once pathogen/danger has been cleared (Figure 4).

Similar to the suppressive effect of $\mathrm{Clq}$ on $\mathrm{T}$ cells acting through $\mathrm{gClqR} / \mathrm{Clq}$ interactions $(51,53)$, we hypothesize that the regulatory effects of $\mathrm{Clq}$ on monocyte/DC precursors may occur via engagement of gC1q. Due to the swift nature of the monocyte to DC transition, regulatory effects of a C1q/C1qR system would occur within a narrow time frame and would be influenced by the microenvironment (steady state or infection or inflammation). The dichotomy of the two apparently opposing roles of C1q in turn are a result of the binding orientation of $\mathrm{Clq}$ - heads versus tails - and the specific receptors engaged ( $g C 1 q R$ versus $c C 1 q R$ ) on the cell surface. Such duality of function would be very similar to the role of surfactant proteins (Sp)-A and Sp-D in the lung, which help maintain the steady state environment via binding to the ITIM-containing SIRP $\alpha$ through their globular head domains or initiate ingestion and pro-inflammatory responses through the collagenous tails and cC1qR (calreticulin)/CD91 (54). Furthermore, although the significance of these motifs has yet to be elucidated, another intriguing observation in this context is the presence of dueling ITAM/ITIM motifs around the tyrosines at positions 224 and 236, respectively on $\mathrm{gClqR}$, which is unique for a molecule that is both an intracellular protein and a cell surface receptor (55). The observations described above together with the finding that there is a clear differential pattern of $\mathrm{C} 1 \mathrm{qR}$ expression during the monocyte to DC transition $(28,35)$, allows us to hypothesize that preferential engagement of distinct regions of $\mathrm{C} 1 \mathrm{q}$ (globular heads versus collagen tails) takes place during different stages of DC growth. Accordingly, the globular head domain of the molecule would mediate regulatory effects of $\mathrm{C1q}$. Since the collagen tail of the C1q in plasma or on the cell surface would be occupied, this association only allows the $\mathrm{Clq}$ subunit to bind $\mathrm{gClqR}$ and not $\mathrm{cClqR}$ on the cell surface. In support, we have found that some or all of the C1q detected on the monocyte surface is part of the $\mathrm{C} 1$ complex (7). Furthermore, cC1qR has been shown to bind Clq only when it undergoes a conformational change (e.g., through immobilization on a surface) (56). Such altered conformation may take place when $\mathrm{Clq}$ binds antigen or immune complexes.

\section{EFFECT OF C1q ON DC DIFFERENTIATION AND FUNCTION}

The development of monocyte-derived DCs from human peripheral blood (PB) is marked by the rapid loss of CD14 (receptor for LPS), up-regulation of CD11c [integrin, $\alpha_{\mathrm{x}}$ (complement component 3 receptor 4 subunit (CR4)], HLA-DR (MHC class II), and co-stimulatory and maturation associated molecules (such as CD86, CD80, CD83) (57-59). Distinct subsets of DC precursor 


\section{Steady State}

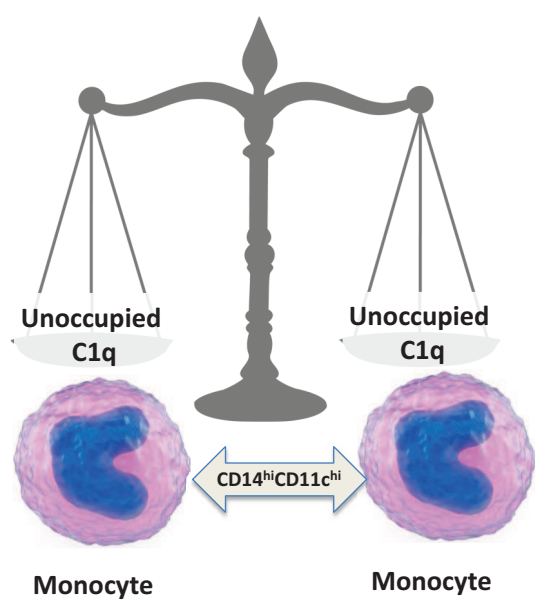

\section{Immunogenic Response}

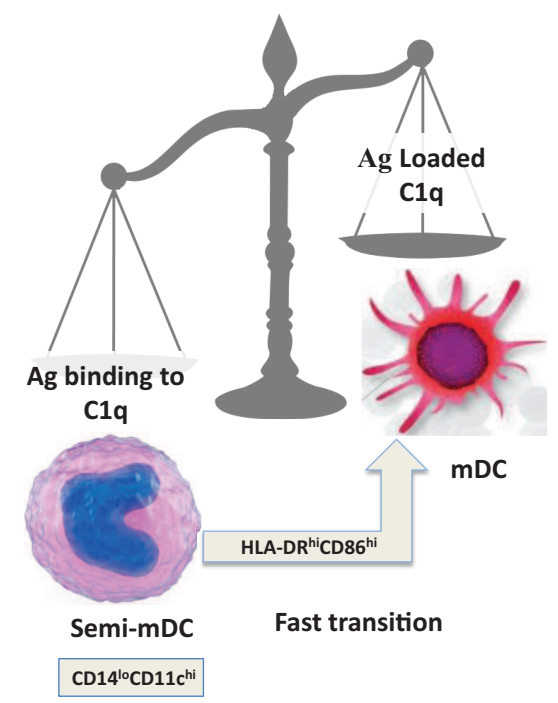

FIGURE 4 | Schematic representation of a fine-tuned balancing act. The transition from steady state to immunogenic response depends on the encounter between an antigen and C1q.

populations have been described to arise from human $\mathrm{PB}$ monocytes treated with GM-CSF + IL-4. These include CD14- ${ }^{-} \mathrm{CD} 11 \mathrm{c}^{+}$, CD $14^{-} \mathrm{CD}_{11 c^{-}}$, and $\mathrm{CD} 16^{ \pm} \mathrm{CD} 14^{+} \mathrm{CD} 11 \mathrm{c}^{+}$cells $(58,59)$. While the majority of iDCs avidly ingest potentially antigenic material as a prerequisite for an immunogenic response, failure to undergo terminal maturation into APCs results in a potentially tolerogenic state $(8,11)$. Targeting of various uptake receptors, notably of Ctype lectin receptors (e.g. DC-SIGN, Langerin, BDCA-2, Dectin-2, etc.) by self-derived Ag on iDCs leads to tolerance by default (8, 11), whereas pathogen-derived Ag might simultaneously signal through TLRs and C-type lectins, thus induce immunity $(8,11)$.

Although somewhat contradictory to the findings of others, which showed that $\mathrm{Clq}$ induces maturation of DCs (60), recent data from our laboratory (35) show that: (i) even in the presence of DC growth factors, exogenously added $\mathrm{Clq}$ is able to inhibit the expression of monocytederived DC maturation markers such as CD86, a required co-stimulatory molecule for $\mathrm{T}$ cell activation (Figures $\mathbf{5 A}, \mathbf{B}$ ); (ii) $\mathrm{Clq}$ promotes the development of distinct iDC subsets CD $14{ }^{\text {hi }}$ CD $11 c^{\text {hi }}$ CD $16^{ \pm}$HLA-DR ${ }^{\text {hi }}$ CD $86^{\text {dim }}$ (Figures 5C,D) compared to $\mathrm{CD} 14^{-} \mathrm{CD} 11 \mathrm{c}^{\text {hi }} \mathrm{CD} 16^{-} \mathrm{HLA}^{-D R^{\text {hi }}}{ }^{\mathrm{CD}} 86^{\text {hi }}$ cells, which develop without C1q. The decreased expression of maturation dependent markers on $\mathrm{Clq}$ treated versus untreated cells substantiates the notion that $\mathrm{Clq}$ alters monocyte to DC differentiation. In addition to these observations, our previously published results $(7,35)$ indicate that Ag-free, extracellular $\mathrm{Clq}$ exerts a regulatory signaling function through engagement of the globular heads by surface $\mathrm{gClqR}$ and thus modulate the differentiation of monocyte-DC precursors and induce the development of CD $14^{\text {hi }}$ CD $11 c^{\text {hi }} \mathrm{CD} 16^{+/-}$cells. Therefore, the decreased expression of DC maturation dependent markers and the increased expression of monocyte associated surface molecules in the presence of $\mathrm{Clq}$ support the concept that the developing cells acquire features of both monocyte and DC. Because C1q is structurally similar to SP-A and SP-D, it might also perform a dual function in that it may help maintain the steady state environment via binding to ITIM-containing surface molecules on cells $(54,61)$ including gC1qR through its globular head domains. Accordingly, occupancy of the gC1q by foreign Ag would induce a conformational change (56) thereby making the collagen tail available for binding to $\mathrm{CC} 1 \mathrm{qR}$. The ensuing cell differentiation and signaling events would thus support rapid DC maturation and immune activation. Conversely, self-derived Ag bound C1q might relay signals through C1q or C-type lectin receptors only, thus inducing a strong tolerogenic response, resulting in development of tolerogenic DC and Treg activation.

\section{INSIGHTS IN TO THE MECHANISMS OF C1q-MEDIATED MONOCYTE/DC SIGNALING}

To date, the information available on the signaling events regulated by $\mathrm{C} 1 \mathrm{q}$ in DCs is very limited. Some studies using murine bone marrow-derived DCs, have shown that C1q treatment suppresses IL-12 production, and reduces the phosphorylation of p38, ERK1/2, c-Jun N-terminal kinase, and extracellular signal-regulated kinase after stimulating the cells with LPS, CpG oligodeoxynucleotides, or anti-CD40 antibodies $(62,63)$. This is contrary to the findings by others that $\mathrm{C} 1 \mathrm{q}$ induces maturation of DCs and secretion of IL-12 and TNF- $\alpha$ and elevated their $\mathrm{T}$ cell stimulating capacity (60). However, a definitive mechanism that mediates C1q signaling in human DCs has not been described. Understanding the molecular mechanisms of how $\mathrm{Clq}$ regulates adaptive immune functions via iDCs in the absence of infection or inflammation is therefore highly significant. Since our data indicate that CD14 levels are markedly increased on 


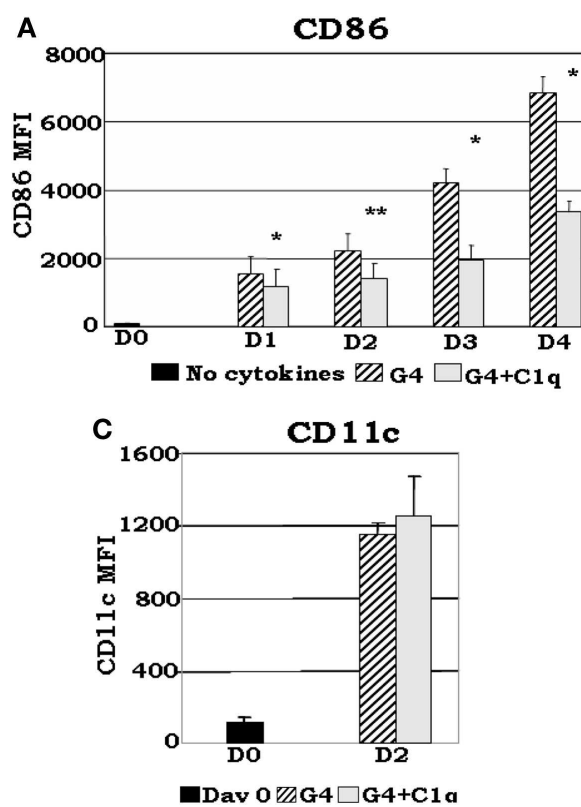

FIGURE 5 | C1q delays GM-CSF + IL-4 induced DC maturation. Monocyte-DCs were isolated and cultured in the presence of GM-CSF + IL-4 (G4) and with or without $25 \mu \mathrm{g} / \mathrm{ml} \mathrm{C1q} \mathrm{(A-C).} \mathrm{For} \mathrm{the} \mathrm{dose}$ response experiments several concentrations of $\mathrm{C} 1 \mathrm{q}$ were added as indicated (D). Cells were collected on the days indicated and analyzed for the expression of CD86, CD83, and CD11c for each condition (A-C), or alternatively, on day $2 \mathrm{HLA}-\mathrm{DR}$ analyses were performed for all C1q doses (D). (A) C1q significantly decreased CD86 expression in monocyte-DCs compared to G4, ${ }^{*} p<0.05,{ }^{*} p<0.01(n=4)$; (B) monocyte-DCs cultured in the presence of $\mathrm{C} 1 \mathrm{q}$ showed a decrease in the percentage of CD83+ cells in comparison with cells cultured in G4 alone. While CD83 expression
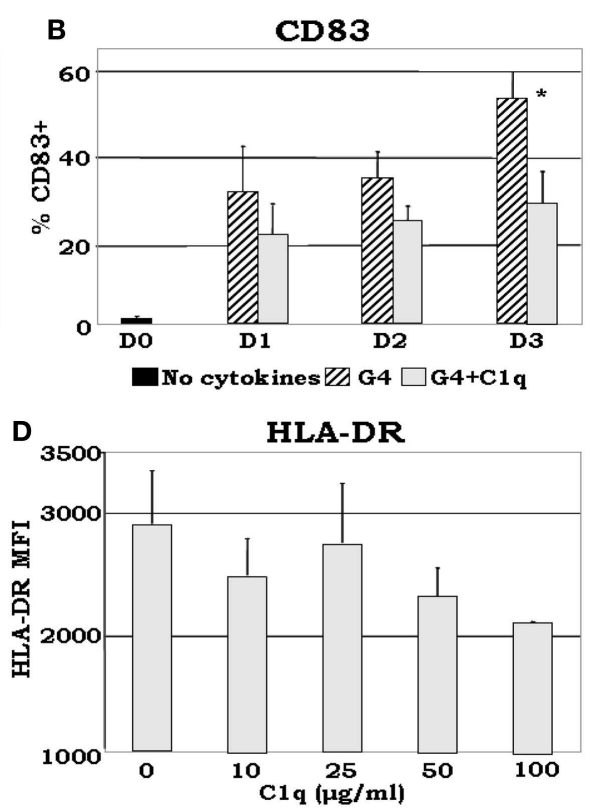

was detected on the surface of these cells, their MFI remained low throughout the days with or without the addition of $\mathrm{C} 1 \mathrm{q}$ (data not shown), ${ }^{*} p<0.05(n=4)$; (C) CD11c expression was increased by day 2 with the addition of $\mathrm{C} 1 \mathrm{q}$ compared to day 0 . There was no significant difference in CD11c expression levels on cells cultured with or without C1q $(n=6)$; (D) dose response analysis revealed that the MFI of HLA-DR+ cells correlates negatively with increasing doses of C1q on day 2. While there was little or no difference in the distribution of HLA-DR on the cells at lower doses $(10-25 \mu \mathrm{g} / \mathrm{ml})$, at higher doses decreased expression was noted $(\mathrm{MFI})(n=3)$. Cells were gated on DR+ cells for all experiments [adapted from Ref. (35)].
mono-DCs when they are cultured in the presence of C1q (35), signaling blockades that may potentially be mediated by CD14 should be evaluated. LPS triggers CD14/TLR4 mediated signaling to induce cell differentiation via TRAF6 and IRAK4 signaling. Although the effect of $\mathrm{C} 1 \mathrm{q}$ on $\mathrm{CD}_{1}{ }^{-}$and TLR-mediated signaling cascades in mono-DCs has not been yet fully investigated, ligand engagement of gClqR ( $\mathrm{HCV}$ core protein and $\mathrm{mAb}$ ) has been shown to increase PI3K activation and Akt phosphorylation in LPS stimulated monocytes in an ERK independent manner (64). Moreover, DC-SIGN, which forms a molecular complex with $\mathrm{Clq}$ and $\mathrm{gClqR}$ on the surface of iDCs (30), has been shown to increase phosphorylation of Raf-1 on Ser338 and Tyr340/341 in a ligand-dependent manner (65). Furthermore, stimulation of DCSIGN with the mannose receptor-1 (MR-1) Ab has been shown to induce activation of the MEK/ERK kinase cascade (66). Whether direct stimulation of C1q participates in these signaling pathways, however, still remains to be investigated.

\section{CONCLUDING REMARKS AND FUTURE OUTLOOK}

The present paper is intended to provoke a debate and inject novel insights into the endlessly intriguing question: Why does homozygous deficiency in C1q predispose an individual to develop SLE and other autoimmune diseases? Although the contribution of $\mathrm{C} 1 \mathrm{q}$ to the process of apoptotic cell clearance is unquestionable - and is supported by robust experimental data - the presence of functionally redundant pathways for removal of apoptotic bodies together with the direct effect of C1q on monocytes/DCs and $\mathrm{T}$ cells would suggest that, in addition to its role in apoptotic clearance, locally secreted C1q - which is DC maturation dependent - determines the activation thresholds of $\mathrm{B}$ and $\mathrm{T}$ cells and that $\mathrm{Clq}$ deficiency causes incomplete maintenance of peripheral tolerance. Therefore, while in the steady state, $\mathrm{Clq}$ would regulate cells during the early DC differentiation events by silencing critical phagocytic or stimulatory markers requisite for antigen presentation (innate immunity), recognition of "danger" would, on the other hand, impart a signal that drives monocytes toward the DC lineage (adaptive immunity). Deficiency in C1q therefore will disrupt this equilibrium. In addition, in the absence of danger signals, C1q may help maintain steady state conditions by skewing DC differentiation toward a "hybrid" cell type with both monocyte-macrophage-like (increased CD14, enhanced phagocytosis, IFN- $\gamma$ secretion) and DC-like ( T cell priming) characteristics. The distinct binding orientation of $\mathrm{Clq}$ (heads versus tail) on the monocytes and iDCs also suggests that specific $\mathrm{C} 1 \mathrm{q} / \mathrm{ClqR}$ interactions - and possibly other surface molecules - may regulate cells as they transition from the monocyte state toward the professional APC state. The presence of C1q together with $\mathrm{C} 1 \mathrm{r}, \mathrm{C} 1 \mathrm{~s}$, and $\mathrm{C} 1-\mathrm{INH}$ on the monocyte surface with its versatile 
antigen-capturing region displayed outwardly also supports the concept that monocytes may represent the first sentinels of danger in the blood.

However, although these postulates are conceptually appealing and are supported by experimental data, future studies, which focus on the role of $\mathrm{ClqRs}, \mathrm{Clq}$, and $\mathrm{Cl}$ within the microenvironment of the monocyte/DC-antigen encounter will be necessary if we are to gain insight into why deficiency in any of the components of $\mathrm{C} 1$ leads to the development of autoimmunity. More importantly, information derived from such studies will not only provide new groundwork for future undertakings related to innate and acquired immunity, but also would give credence to targeted modulation of C1/C1q-mediated DC function as new treatment option aiming at alleviating DC-driven autoimmune responses.

\section{ACKNOWLEDGMENTS}

This work was supported in part by grants from the National Institutes of Health (R01 AI 060866 and R01 AI-084178).

\section{REFERENCES}

1. Swirski FK, Nahrendorf M, Etzrodt M, Wildgruber M, Cortez-Retamozo V, Panizzi P, et al. Identification of splenic reservoir monocytes and their deployment to inflammatory sites. Science (2009) 325:612-6. doi:10.1126/science. 1175202

2. Ziegler-Heitbrock L, Ancuta P, Crowe S, Dalod M, Grau V, Hart DN, et al. Nomenclature of monocytes and dendritic cells in blood. Blood (2010) 116:74-80. doi:10.1182/blood-2010-02-258558

3. Medzhitov R. Toll-like receptors and innate immunity. Nat Rev Immunol (2001) 1:135-45. doi:10.1038/35100529

4. Ghebrehiwet B, Peerschke EI. cC1qR (calreticulin) and gC1qR/p33: ubiquitously expressed multi-ligand binding cellular proteins involved in inflammation and infection. Mol Immunol (2004) 41:173-83. doi:10.1016/j.molimm.2004.03.014

5. Ghebrehiwet B, Hosszu KK, Valentino A, Peerschke EI. The C1q family of proteins: insights into the emerging non-traditional functions. Front Immunol (2012) 3:52. doi:10.3389/fimmu.2012.00052

6. Randazzo BP, Dattwyler RJ, Kaplan AP, Ghebrehiwet B. Synthesis of C1 inhibitor (C1-INA) by a human monocyte-like cell line, U937. J Immunol (1985) 135:1313-9.

7. Hosszu KK, Valentino A, Ji Y, Matkovic M, Pednekar L, Rehage N, et al. Cell surface expression and function of the macromolecular $\mathrm{C} 1$ complex on the surface of human monocytes. Front Immunol (2012) 3:38-43. doi:10.3389/fimmu. 2012.00038

8. Inaba K, Pack M, Inaba M, Sakuta H, Isdell F, Steinman RM. High levels of major histocompatibility complex II-self peptide complex on dendritic cells from the T cell areas of lymph nodes. J Exp Med (1997) 186:665-72. doi:10.1084/jem.186.5.665

9. Banchereau J, Steinman R. Dendritic cells and the control of immunity. Nature (1998) 392:245-52. doi:10.1038/32588

10. Albert ML, Pearce SF, Francisco LM, Sauter B, Roy P, Silverstein RL, et al. Immature dendritic cells phagocytose apoptotic cells via alpha 5 and CD36, and crosspresent antigens to cytotoxic T lymphocytes. J Exp Med (1998) 188:1359-68. doi:10.1084/jem.188.7.1359

11. Steinman RM, Turley S, Mellman I, Inaba K. The induction of tolerance by dendritic cells that have captured apoptotic cells. J Exp Med (2000) 191:411-6. doi:10.1084/jem.191.3.411

12. Kadowaki N, Ho S, Antonenko S, Malefyt RW, Kastelein RA, Bazan F, et al. Subsets of human dendritic cells precursors express different toll-like receptors and respond to different microbial antigens. J Exp Med (2001) 194:863-9. doi:10.1084/jem.194.6.863

13. Figdor CG, van Kooyk Y, Adema GJ. C-type lectin receptors on dendritic cells and Langerhans cells. Nat Rev Immunol (2002) 2:77-84. doi:10.1038/nri827

14. Steinman RM, Hawiger D, Nussensweig MC. Tolerogenic dendritic cells. Ann Rev Immunol (2003) 21:685-711. doi:10.1146/annurev.immunol.21.120601.141040
15. Pettit AR, Thomas R. Dendritic cells: the driving force behind autoimmunity in rheumatoid arthritis? Immunol Cell Biol (1999) 77:420-7. doi:10.1046/j.14401711.1999.00855.x

16. Kapsenberg ML. Dendritic-cell control of pathogen-driven T-cell polarization. Nat Rev Immunol (2003) 3:984-93. doi:10.1038/nri1246

17. Moser M. Dendritic cells in immunity and tolerance - do they display opposite functions? Immunity (2003) 19:5-8. doi:10.1016/S1074-7613(03)00182-1

18. Scandella E, Ludewig B. Dendritic cells and autoimmunity. Transfus Med Hemother (2005) 32:363-8. doi:10.1159/000089124

19. Bensa JC, Reboul A, Colomb MG. Biosynthesis in vitro of complement subcomponents $\mathrm{Clq}, \mathrm{C} 1 \mathrm{~s}$ and $\mathrm{C} 1$ inhibitor by resting and stimulated human monocytes. Biochem J (1983) 216:385-92.

20. Tenner AJ, Volkin DB. Complement subcomponent C1q secreted by cultured human monocytes has a subunit structure identical with that of serum C1q. Biochem J (1986) 233:451-8.

21. Drouet C, Reboul A. Biosynthesis of C1r and Cls subcomponents. Behring Inst Mitt (1989) 84:80-8.

22. Gulati P, Lemercier C, Guc D, Lappin D, Whaley K. Regulation of the synthesis of C1 subcomponents and C1-inhibitor. Behring Inst Mitt (1993) 93:196-203.

23. Lu J, Le Y, Kon OL, Chan J, Lee SH. Biosynthesis of human ficolin, an Escherichia coli-binding protein, by monocytes: comparison with the synthesis of two macrophage-specific proteins, $\mathrm{Clq}$ and the mannose receptor. Immunology (1996) 89:289-94.

24. Moosig F, Damm F, Knorr-Spahr A, Ritgen M, Zeuner RA, Kneba M, et al. Reduced expression of C1q-mRNA in monocytes from patients with systemic lupus erythematosus. Clin Exp Immunol (2006) 146:409-16. doi:10.1111/j. 1365-2249.2006.03225.x

25. Loos M. Biosynthesis of the collagen-like C1q molecule and its receptor function for $\mathrm{Fc}$ and polyanionic molecules on macrophages. Curr Top Microb Immuno (1983) 102:1-56.

26. Kaul M, Loos M. Collagen-like complement component $\mathrm{Clq}$ is a membrane protein of human monocyte-derived macrophages that mediates endocytosis. J Immunol (1995) 155:5795-802.

27. Kaul M, Loos M. Expression of membrane C1q in human monocyte-derived macrophages is developmentally regulated and enhanced by interferon-gamma. FEBS Lett (2001) 500:91-8. doi:10.1016/S0014-5793(01)02592-3

28. Vegh Z, Goyarts EC, Rozengarten K, Mazumder A, Ghebrehiwet B. Maturationdependent expression of Clq-binding proteins on the cell surface of human monocyte-derived dendritic cells. Int Immunopharmacol (2003) 3:345-57. doi:10.1016/S1567-5769(02)00211-4

29. Castellano G, Woltman AM, Nauta AJ, Roos A, Trouw LA, Seelen MA, et al. Maturation of dendritic cells abrogates Clq production in vivo and in vitro. Blood (2004) 103:3813-20. doi:10.1182/blood-2003-09-3046

30. Hosszu KK, Valentino A, Vinayagasundaram U, Vinayagasundaram R, Joyce MG, Ji Y, et al. DC-SIGN, Clq and gClqR form a tri-molecular receptor complex on the surface of monocyte-derived immature dendritic cells. Blood (2012) 120:1228-36. doi:10.1182/blood-2011-07-369728

31. Walport MJ, Davies KA, Botto M. C1q and systemic lupus erythematosus. Immunobiology (1998) 199:265-85. doi:10.1016/S0171-2985(98)80032-6

32. Walport MJ. Complement and systemic lupus erythematosus. Arthritis Res (2002) 4(Suppl 3):S279-93. doi:10.1186/ar586

33. Pickering MC, Botto M, Taylor PR, Lachmann PJ, Walport MJ. Systemic lupus erythematosus, complement deficiency, and apoptosis. Adv Immunol (2000) 76:227-34. doi:10.1016/S0065-2776(01)76021-X

34. Ghebrehiwet B, Peerschke EI. Role of $\mathrm{Clq}$ and $\mathrm{Clq}$ receptors in the pathogenesis of systemic lupus erythematosus. Curr Dir Autoimmun (2004) 7:87-97. doi:10.1159/000075688

35. Hosszu KK, Santiago-Schwarz F, Peerschke EI, Ghebrehiwet B. Evidence that a $\mathrm{Clq} / \mathrm{ClqR}$ system regulates monocyte-derived dendritic cell differentiation at the interface of innate and acquired immunity. Innate Immun (2010) 16:115-27. doi: $10.1177 / 1753425909339815$

36. Lahita RG. Systemic Lupus Erythematosus. 3rd ed. San Diego, CA: Academic Press (1999).

37. Liu C-C, Navratil JS, Sabine JM, Ahearn JM. Apoptosis, complement and systemic lupus erythematosus: a mechanistic view. In: Tsokos GC, editor. Complement in Autoimmunity. (Vol. 7), Basel: Karger (2004). p. 49-86.

38. Nishino H, Shibuya K, Nishida Y, Mushimoto M. Lupus erythematosus-like syndrome with selective C1q complete deficiency of C1q. Ann Intern Med (1981) 95:322-4. doi:10.7326/0003-4819-95-3-322 
39. Komatsu A, Komazawa M, Murakami M, Nagaki Y. A case of selective C1qdeficiency with SLE-like symptoms. J Jpn Pediatr Soc (1982) 86:23-6.

40. Botto M. Clq knockout mice for the study of complement deficiency in autoimmune disease. Exp Clin Immunogenet (1998) 15:231-4. doi:10.1159/000019076

41. Kishore U, Kojouharova MS, Reid KBM. Recent progress in the understanding of the structure-function relationships of the globular head region of C1q. Immunobiology (2002) 205:355-64. doi:10.1078/0171-2985-00138

42. Nauta AJ, Trouw LA, Daha MR, Tijsma O, Nieuwland R, Schwaeble WJ, et al. Direct binding of C1q to apoptotic cells and cell blebs induces complement activation. Eur J Immunol (2002) 32:1726-36. doi:10.1002/1521-4141(200206) 32:6<1726::AID-IMMU1726>3.0.CO;2-R

43. Gaboriaud C, Païdassi H, Frachet P, Tacnet-Delorme P, Thielens NM, Arlaud GJ. C1q: a versatile pattern recognition molecule and sensor of altered self. In: Kilpatrick D, editor. Collagen-Related Lectins in Innate Immunity. (Vol. 81), New York: Research Signpost (2007). p. 1-15.

44. Païdassi H, Tacnet P, Garlatti V, Darnault C, Ghebrehiwet B, Gaboriaud C, et al. $\mathrm{Clq}$ binds phosphatidylserine and likely acts as a multiligand bridging molecule in apoptotic cell recognition. J Immunol (2008) 180:2329-38. doi:10.4049/jimmunol.180.4.2329

45. Bally I, Ancelet S, Moriscot C, Gonnet F, Mantovani A, Daniel R, et al. Expression of recombinant human complement $\mathrm{Clq}$ allows identification of the C1r/C1s-binding sites. Proc Natl Acad Sci U S A (2013) 110:8650-5. doi:10.1073/pnas.1304894110

46. Casciola-Rosen LA, Anhalt G, Rosen A. Autoantigens targeted in systemic lupus erythematosus are clustered in two populations of surface structures on apoptotic keratinocytes. J Exp Med (1994) 179:1317-30. doi:10.1084/jem.179.4.1317

47. Korb LC, Ahearn JM. C1q binds directly and specifically to surface blebs of apoptotic human keratinocytes: complement deficiency and systemic lupus erythematosus revisited. J Immunol (1997) 158:4527-9.

48. Ogden CA, deCathelineau A, Hoffmann PR, Braton D, Ghebrehiwet B, Fadok VA, et al. Clq and mannose binding lectin (MBL) engagement of cell surface calreticulin and CD91 initiates macropinocytosis and uptake of apoptotic cells. J Exp Med (2001) 194:781-95. doi:10.1084/jem.194.6.781

49. Vandivier RW, Ogden CA, Fadok VA, Hoffmann PR, Brown KK, Botto M, et al. Role of surfactant proteins $\mathrm{A}, \mathrm{D}$, and $\mathrm{Clq}$ in the clearance of apoptotic cells in vivo and in vitro: calreticulin and CD91 as a common collectin receptor complex. J Immunol (2002) 169:3978-86. doi:10.4049/jimmunol.169.7.3978

50. Nauta AJ, Castellano G, Xu W, Woltman AM, Borrias MC, Daha MR, et al. Opsonization with $\mathrm{Clq}$ and mannose-binding lectin targets apoptotic cells to dendritic cells. J Immunol (2004) 173:3044-50. doi:10.4049/jimmunol.173.5. 3044

51. Chen A, Gaddipati S, Volkman DJ, Peerschke EIB, Ghebrehiwet B. Human T cells possess specific receptors for $\mathrm{Clq}$ : role in activation and proliferation. J Immunol (1994) 153:1430-40.

52. Szabo J, Cervenak L, Toth FD, Prohaszka Z, Horvath L, Kerekes K, et al. Soluble $\mathrm{gClq}-\mathrm{R} / \mathrm{p} 33$, a cell protein that binds to the globular "heads" of C1q, effectively inhibits the growth of HIV-1 strains in cell cultures. Clin Immunol (2001) 99:222-31. doi:10.1006/clim.2001.5013

53. Kittlesen DJ, Chianese-Bullock KA, Yao ZQ, Braciale TJ, Hahn YS. Interaction between complement receptor $\mathrm{gCl} \mathrm{qR}$ and hepatitis $\mathrm{C}$ virus core protein inhibits T-lymphocyte proliferation. J Clin Immunol (2000) 106:1239-49.

54. Gardai SJ, Xiao YQ, Dickinson M, Nick JA, Voelker DR, Greene KE, et al. By binding SIRPalpha or calreticulin/CD91, lung collectins act as dual function surveillance molecules to suppress or enhance inflammation. Cell (2003) 115:13-23. doi:10.1016/S0092-8674(03)00758-X

55. Ghebrehiwet B, Jesty J, Vinayagasundaram U, Vinayagasundaram R, Ji Y, Valentino A, et al. Targeting gClqR domains for therapy against infection and inflammation. Adv Exp Med Biol (2013) 735:97-110. doi:10.1007/978-1-46144118-2_6

56. Steino A, Jorgensen CS, Laursen I, Houen G. Interaction of C1q with the receptor calreticulin requires a conformational change in C1q. Scand J Immunol (2004) 59:485-95. doi:10.1111/j.0300-9475.2004.01425.x

57. Shortman K, Caux C. Dendritic cell development: multiple pathways to nature's adjuvants. Stem Cells (1997) 15:409-19. doi:10.1002/stem.150409

58. Banchereau J, Briere F, Caux C, Davoust J, Lebecque S, Liu Y-J, et al. Immunobiology of dendritic cells. Annu Rev Immunol (2000) 18:767-811. doi:10.1146/ annurev.immunol.18.1.767

59. Reid SD, Penna G, Adorini L. The control of T cell responses by dendritic cell subsets. Curr Opin Immunol (2000) 12:114-21. doi:10.1016/S0952-7915(99) 00059-X

60. Csomor E, Bajtay Z, Sandor N, Krsitof K, Arlaud GJ, Thiel S, et al. Complement protein $\mathrm{Clq}$ induces maturation of human dendritic cells. Mol Immunol (2007) 44:3389-97. doi:10.1016/j.molimm.2007.02.014

61. Pastva AM, Wright JR, Williams KL. Immunomodulatory roles of surfactant proteins A and D: implications in lung disease. Proc Am Thorac Soc (2007) 4:252-7. doi:10.1513/pats.200701-018AW

62. Yamada M, Oritani K, Kaisho T, Ishikawa J, Yoshida H, Takahashi I, et al. Complement C1q regulates LPS-induced cytokine production in bone marrowderived dendritic cells. Eur J Immunol (2004) 34:221-30. doi:10.1002/eji. 200324026

63. Baruah P, Dumitriu IE, Malik TH, Cook HT, Dyson J, Scott D, et al. C1q enhances IFN- $\gamma$ production by antigen specific T cells via the CD40 co-stimulatory pathway on dendritic cells. Blood (2009) 113:3485-93. doi:10.1182/blood-2008-06164392

64. Waggoner SN, Cruise MW, Kassel R, Hahn YS. gC1q receptor ligation selectively down-regulates human IL-12 production through activation of the phosphoinositide 3-kinase pathway. J Immunol (2005) 175:4706-14. doi:10.4049/ jimmunol.175.7.4706

65. Gringhuis SI, den Dunnen J, Litjens M, van Het Hof B, van Kooyk Y, Geijtenbeek TB. C-type lectin DC-SIGN modulates toll-like receptor signaling via Raf1 kinase-dependent acetylation of transcription factor NF-kappaB. Immunity (2007) 26:605-16. doi:10.1016/j.immuni.2007.03.012

66. Caparros E, Munoz P, Sierra-Filardi E, Serrano-Gomez D, Puig-Kröger A, Rodriguez-Fernandez JL, et al. DC-SIGN ligation on dendritic cells results in ERK and PI3K activation and modulates cytokine production. Blood (2006) 107:3950-8. doi:10.1182/blood-2005-03-1252

Conflict of Interest Statement: The authors declare that the research was conducted in the absence of any commercial or financial relationships that could be construed as a potential conflict of interest.

Received: 22 April 2014; accepted: 28 May 2014; published online: 26 June 2014. Citation: Ghebrehiwet B, Hosszu KK, Valentino A, Ji Y and Peerschke EIB (2014) Monocyte expressed macromolecular $C 1$ and $C 1 q$ receptors as molecular sensors of danger: implications in SLE. Front. Immunol. 5:278. doi: 10.3389/fimmu.2014.00278 This article was submitted to Molecular Innate Immunity, a section of the journal Frontiers in Immunology.

Copyright $@ 2014$ Ghebrehiwet, Hosszu, Valentino, Ji and Peerschke. This is an openaccess article distributed under the terms of the Creative Commons Attribution License (CC BY). The use, distribution or reproduction in other forums is permitted, provided the original author(s) or licensor are credited and that the original publication in this journal is cited, in accordance with accepted academic practice. No use, distribution or reproduction is permitted which does not comply with these terms. 